\title{
Effect of delayed time, surface treatment, and repair material on shear bond strength of repaired bis-acryl composite resin
}

\author{
Ji-su Park, Jae-In Lee* \\ Department of Prosthodontics, College of Dentistry, Wonkwang University, Iksan, Republic of Korea
}

Purpose: The aim of this study was to evaluate the effect of delayed time, surface treatment, and repair materials on repair of bisacryl composite resin through comparison of shear bond strength and to evaluate the utility of bis-acryl composite resin repair using polymethyl methacrylate resin. Materials and Methods: A total of 90 bis-acryl composite resin specimens were fabricated and classified into 9 test groups, each of 10 pieces according to delayed time, surface treatment and repair material. The shear bond strength of each specimen was measured using a universal testing machine immediately after fabrication and analyzed using a statistical analysis program (IBM SPSS statistics 20). After the shear bond strength measurement, the fracture surface of the specimen was observed. Results: The highest shear bond strength (17.54 $\pm 3.14 \mathrm{MPa}$ ) was observed in the experimental group bonded immediately with a light-curing flowable composite resin using a bonding agent. Conclusion: When repairing bis-acryl composite resin, it is necessary to consider whether to remake according to the delayed time. For effective repair, it is desirable to consider appropriate materials and surface treatment methods according to the site or purpose of use. (J Dent Rehabil Appl Sci 2018;34(2):89-96)

Key words: bis-acryl composite resin; polymethylmethacrylate resin; bonding agent; silane; provisional restoration repair

\section{서론}

임시 수복물은 치수와 치주 건강을 보호하고, 적합 한 보철물 형태를 얻기 위한 주변 연조직 치유를 도모 하며, 지대치의 이동을 방지하고, 올바른 교합양식 설정 을 위한 역할을 한다. 임시 고정성 수복물에 보편적으 로 사용되는 재료에는 다음과 같은 아크릴릭 레진 종류 들이 있다. (1) polymethyl methacrylate (PMMA) resin, (2) polyethyl methacrylate (PEMA) resin, (3) polyvinyl methacrylate resin, (4) bis-acryl composite resin, (5) visible light-cured urethane dimethacrylates. ${ }^{1}$

이러한 재료들 중에서 자주 쓰이는 자가 중합 아크릴

*Correspondence to: Jae-In Lee

Associate Professor, Department of Prosthodontics, College of Dentistry, Wonkwang University, 77 Doonsan-ro, Seo-gu, Daejeon, 35233, Republic of Korea Tel: +82-42-366-1160, Fax: +82-42-366-1115, E-mail: cash78@empas.com Received: February 6, 2018/Last Revision: February 22, 2018/Accepted: February 28,2018
\end{abstract}

릭 레진인 PMMA 레진은 간단한 조작만으로 결함을 쉽 게 재건할 수 있고 가격이 저렴하다는 장점을 가지지만, 불쾌한 냄새, 심한 중합 수축, 짧은 작업 시간, 중합 시 발 열로 인한 치수 자극 등의 단점도 가진다. ${ }^{2,3}$ 한편, 1990년 대 후반에 소개된 비스 아크릴 복합 레진은 자동 혼합 시 린지(automix syringes) 형태로 제공되어 가격이 비싸지 만, 혼합이 편리하고, 최소의 수축, 낮은 발열 반응, 뛰어 난 색 안정성을 보이는 장점이 있다. ${ }^{4}$

구강 내에서 제거할 때나 제작 도중, 혹은 기능 시에 임 시 수복물이 종종 파절되곤 하는데, ${ }^{5}$ 그 원인들로는 부 적절한 횡적인 응력이나 과도한 응력, 피로 파절 등이 있 다. ${ }^{6,7}$ 오래되거나 파절된 레진을 수리하는 경우 새로 제 
작된 것 보다 물성이 떨어지므로, 임상가는 목적과 효율 성에 따라 임시 수복물을 새로 제작할 것인지, 수리할 것 인지를 결정하게 된다. 그 동안 레진의 효과적인 수리를 위해 접착제(bonding agent), 실란(silane) 등의 표면처리 방법들이 소개되었다. ${ }^{8,9}$

비스 아크릴 복합 레진 간의 결합강도는 낮아서 수리 시 비스 아크릴 복합 레진을 사용하는 것이 어려우므로 그것이 결정적인 단점으로 지적되어 왔다. 이 한계를 극 복하기 위해 그 동안 비스 아크릴 복합 레진의 수리에 광 중합형 유동성 복합 레진(light curing flowable composite resin)의 사용이 추천되었다. ${ }^{10}$

비스 아크릴 복합 레진의 수리에 있어서 광중합형 유동 성 복합 레진을 사용하는 것은 가격이 비싸서 임시 수복 용 레진의 수리에 사용하는 것이 비경제적이며, 수복물 내 면의 이장재료로는 사용하기 어렵다. 그러므로 본 연구에 서는 비스 아크릴 복합 레진의 수리 시 지연시간, 표면처 리, 수리재료가 전단 결합강도에 미치는 영향을 알아보 고, 가격이 저렴하고 다루기 쉬운 PMMA 레진을 이용한 비스 아크릴 레진 수리의 효용성을 평가하고자 한다.

\section{연구 재료 및 방법}

\section{1. 시편 제작}

본 실험의 시편은 국제표준인 ISO/TS 11405 (치과재 료와 치아의 접착시험)를 참고하여 제작되었다.

1) 비스 아크릴 레진 베이스 제작

직경 $8 \mathrm{~mm}$, 높이 $10 \mathrm{~mm}$ 의 원기둥이 형성된 실리콘 몰 드에 비스 아크릴 복합 레진(Protemp 4, 3M ESPE, St. $\mathrm{Paul}, \mathrm{USA}$ )을 주입하여 제조사의 지시에 따라 5 분간 중 합하였다. 직경 $22 \mathrm{~mm}$, 높이 $16 \mathrm{~mm}$ 의 원기둥이 형성된 스테인리스 스틸 몰드에 투명한 아크릴릭 레진(Orthojet, Lang dental, Wheeling, USA)을 $6 \mathrm{~mm}$ 높이만 주입 하여 중합한 후, 그 위에 비스 아크릴 복합 레진 시편을 놓고 포매 하였다. 이러한 방법으로 총 90 개의 시편을 제 작하였다.

\section{2) 수리 시간 지연}

\#220-grit의 사포를 이용하여 비스 아크릴 레진 베이 스의 표면을 평탄하게 하고 표면의 산소억제층(oxygen inhibited layer)을 제거한 뒤, 세척하여 건조하였다. 90개
의 시편 중 30 개는 $37^{\circ} \mathrm{C}$ 의 증류수에 15 일간 보관 후, 표 면처리 및 수리 레진 접착 과정을 진행하였다.

\section{3) 표면처리}

\#220-grit의 사포를 이용하여 비스 아크릴 레진 베이 스의 표면을 평탄하게 하고 표면의 산소억제층을 제거한 뒤, 세척하여 건조하였다. 그리고 중앙에 직경 $2.3 \mathrm{~mm}$ 의 구멍이 딿린 셀로판 테이프를 표면에 부착하였다.

\section{3-1) 접착제의 적용}

접착제(Clearfil SE bond, Kuraray dental, Kurashiki, Japan)를 microbrush를 이용하여 비스 아크릴 레진 베이 스 표면에 제조사의 지시에 따라 도포하고 건조하였다. 그리고 광중합기(VALO cordless curing light, Ultradent, South Jordan, USA)를 이용하여 10 초간 $1000 \mathrm{~mW} / \mathrm{cm}^{2}$ 의 세기로 광중합을 시행하였다.

\section{3-2) 실란의 적용}

실란(Monobond S, Ivoclar vivadent, Ivoclar vivadent, Schaan, Liechtenstein)을 microbrush를 이용하여 비스 아크릴 레진 베이스 표면에 제조사의 지시에 따라 60 초 간 적용 후 건조하였다.

\section{4) 수리 재료의 접착}

중앙에 직경 $2.3 \mathrm{~mm}$ 의 구멍이 뚫린 직경 $22 \mathrm{~mm}$, 높이 $16 \mathrm{~mm}$ 의 원기둥이 형성된 실리콘 몰드에 비스 아크릴 레진 베이스를 삽입한 후 수리 레진 접착을 시행하였다.

\section{4-1) PMMA 레진의 접착}

PMMA 레진(Tokuso curefast, Tokuyama dental, Tokyo, Japan)의 분말과 액을 제조사의 지시에 따라 혼합 하여 직경 $2.3 \mathrm{~mm}$ 의 구멍에 주입한 후 중합하였다. 중합 완료 후 셀로판테이프를 제거하고 접착면 주변을 정리하 였다(Fig. 1).

\section{4-2) 광중합형 유동성 복합 레진의 접착}

광중합형 유동성 복합 레진(Estelite sigma quick OA2, Tokuyama dental, Tokyo, Japan)을 주입한 후 광중합기 를 이용하여 20 초간 $1000 \mathrm{~mW} / \mathrm{cm}^{2}$ 의 세기로 광중합을 시행하였고, 몰드를 제거한 후 10 초간 추가로 광중합을 시행하였다. 중합 완료 후 셀로판테이프를 제거하고 접 착면 주변을 정리하였다(Fig. 1). 


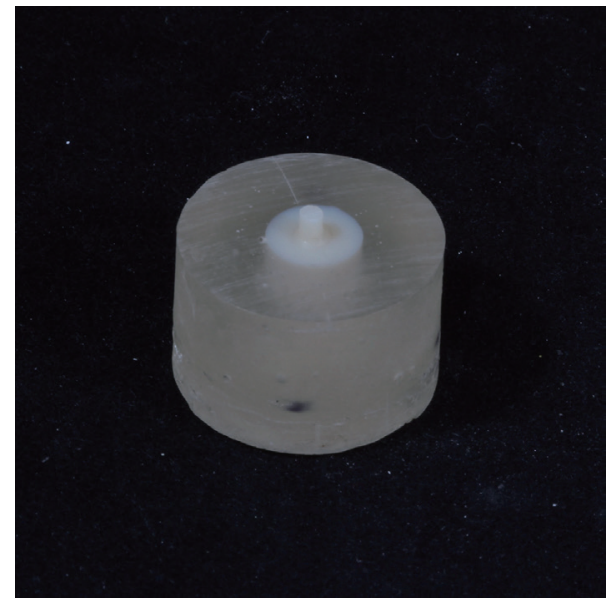

Fig. 1. Fabricated specimen.

시편의 실험군 분류는 다음 표와 같으며, 각 군별로 10 개의 시편을 제작하였다(Table 1).

\section{2. 전단 결합강도 측정}

전단 결합강도 측정을 위해 만능시험기(Z020, ZwickRoell, Ulm, Germany)를 압축 모드(compression mode) 로 사용하였고, 계면에 평행한 방향으로 결합 실패가 일어날 때까지 힘을 가하였으며, cross head speed는 1 $\mathrm{mm} / \mathrm{min}$ 였다(Fig. 2). 전단 결합강도는 접착면의 파절이 일어날 때까지의 최대 강도로 $\mathrm{MPa}$ 단위로 계산되었다.

\section{3. 파절 단면의 관찰}

전단 결합강도 측정 후, 파절 단면을 관찰하였다. 파절 양상을 접착 파절(adhesive failure), 응집 파절(cohesive

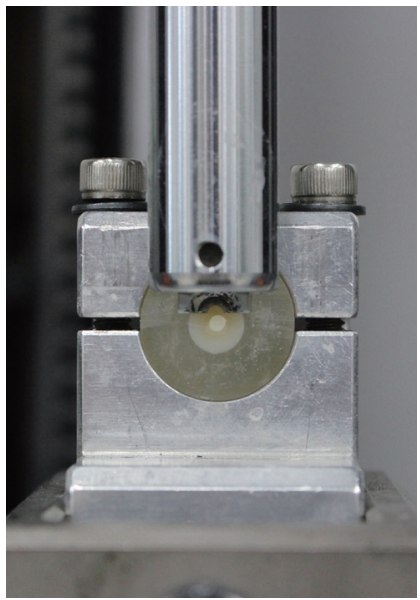

Fig. 2. Shear bond strength test.

failure), 혼합 파절(mixed failure)로 나누었다. 접착 파절 은 계면의 파절, 응집 파절은 레진 내부의 파절, 혼합 파 절은 응집과 접착 파절이 혼재된 양상을 보이는 경우로 하였다.

\section{4. 통계 분석}

각 그룹별 시편들의 전단 결합강도 값들을 통계분석 프로그램(IBM SPSS statistics 20, IBM, Armonk, New York, USA)을 이용하여 분석하였다. 각 실험 군별 전단 결합강도 값의 통계적 유의성은 일원배치 분산분석(oneway ANOVA)을 통해 분석하였고, 사후검정은 Tukey $\mathrm{HSD}$ test 를 통해 시행되었다 $(P=0.05)$. 전단 결합강도 값과 각 파절 양상 간의 상관성은 Spearman의 순위상관 분석을 통해 분석하였다.

Table 1. Classification of experiment group

\begin{tabular}{ccll}
\hline Group & Subgroup & N & \multicolumn{1}{c}{ Composition } \\
\hline \multirow{2}{*}{ A } & A1 & 10 & Bis-acryl resin + PMMA resin (15 days delayed) \\
& A2 & 10 & Bis-acryl resin + Bonding agent + PMMA resin (15 days delayed) \\
& A3 & 10 & Bis-acryl resin + Silane + PMMA resin (15 days delayed) \\
B & B1 & 10 & Bis-acryl resin + PMMA resin \\
& B2 & 10 & Bis-acryl resin + Bonding agent + PMMA resin \\
& B3 & 10 & Bis-acryl resin + Silane + PMMA resin \\
& C1 & 10 & Bis-acryl resin + Flowable resin \\
& C2 & 10 & Bis-acryl resin + Bonding agent + Flowable resin \\
& C3 & 10 & Bis-acryl resin + Silane + Flowable resin \\
\hline
\end{tabular}




\section{결과}

\section{1. 전단 결합강도 비교 (Table 2)}

모든 실험군의 전단 결합강도 평균값은 아래와 같다. 제작 직후 접착제를 이용하여 광중합형 유동성 복합 레 진을 접착한 $\mathrm{C} 2$ 군에서 가장 높은 전단 결합강도 값을 보였다.

1) 지연시간에 따른 전단 결합강도 비교

지연시간이 전단 결합강도에 미치는 영향을 알아보기 위해 Group A와 Group B의 전단 결합강도 값들을 비교 하였다. 아무것도 처리하지 않은 군(A1, B1)과 접착제를 처리한 군(A2, B2)에서는 통계적으로 유의한 차이가 없

Table 2. One-way ANOVA and post hoc Tukey HSD test result of all experimental groups (MPa)

\begin{tabular}{ccc}
\hline Group & Subgroup & Mean \pm SD \\
\hline \multirow{2}{*}{ A } & A1 & $5.45 \pm 2.25^{\mathrm{a}}$ \\
& A2 & $9.46 \pm 5.56^{\mathrm{bc}}$ \\
& A3 & $7.67 \pm 2.60^{\mathrm{ab}}$ \\
B & B1 & $6.39 \pm 1.40^{\mathrm{ab}}$ \\
& B2 & $12.29 \pm 1.90^{\mathrm{cd}}$ \\
& B3 & $12.03 \pm 2.16^{\mathrm{cd}}$ \\
C & C1 & $9.50 \pm 1.45^{\mathrm{bc}}$ \\
& C2 & $17.54 \pm 3.14^{\mathrm{e}}$ \\
& C3 & $15.20 \pm 4.16^{\mathrm{de}}$ \\
\hline
\end{tabular}

The same superscripted letters indicate the values that are not significantly different $(P>0.05)$
었고 $(P>0.05)$, 실란을 처리한 군(A3, B3)에서는 B3의 전단 결합강도 값이 유의하게 크게 나타났다 $(P<0.05)$.

2) 표면 처리에 따른 전단 결합강도 비교

표면처리가 전단 결합강도에 미치는 영향을 알아보기 위해 각 Group별로 Subgroup 간의 전단 결합강도 값들 을 비교하였다. Group A, B, C 모두에서 아무것도 처리 하지 않은 군(Subgroup 1)에 비해 접착제와 실란을 처리 한 군(Subgroup 2,3)의 전단 결합강도 값이 유의성 있게 높았다 $(P<0.05)$.

\section{3) 수리재료에 따른 전단 결합강도 비교}

수리재료가 전단 결합강도에 미치는 영향을 알아보기 위해 Group B와 Group C의 전단 결합강도 값들을 비 교하였다. 아무것도 처리하지 않은 경우와 실란을 처리 한 경우에는 수리재료에 따른 유의성 있는 차이가 나타 나지 않았고 $(P>0.05)$, 접착제를 처리한 경우 수리재료 로 PMMA 레진을 사용했을 때보다 광중합형 유동성 복 합 레진을 사용하였을 경우의 전단 결합강도 값이 유의 성 있게 높았다 $(P<0.05)$.

\section{2. 파절 단면의 관찰(Fig. 3)}

각 시편들의 파절 양상은 다음 표와 같다(Table 3). 접 착 파절(Fig. $3 \mathrm{~A})$ 은 $\mathrm{A} 1$ 군에서 가장 많이 관찰되었고, 응 집 파절(Fig. $3 \mathrm{~B}$ )은 $\mathrm{A} 2$ 군에서 가장 많이 관찰되었다. 혼 합 파절(Fig. $3 \mathrm{C})$ 은 $\mathrm{A} 2, \mathrm{C} 2$ 군에서 가장 많이 관찰되었 다. 전단 결합강도 값과 각 파절 양상 간의 상관성은 나 타나지 않았다 $(P>0.05$, Table 4).
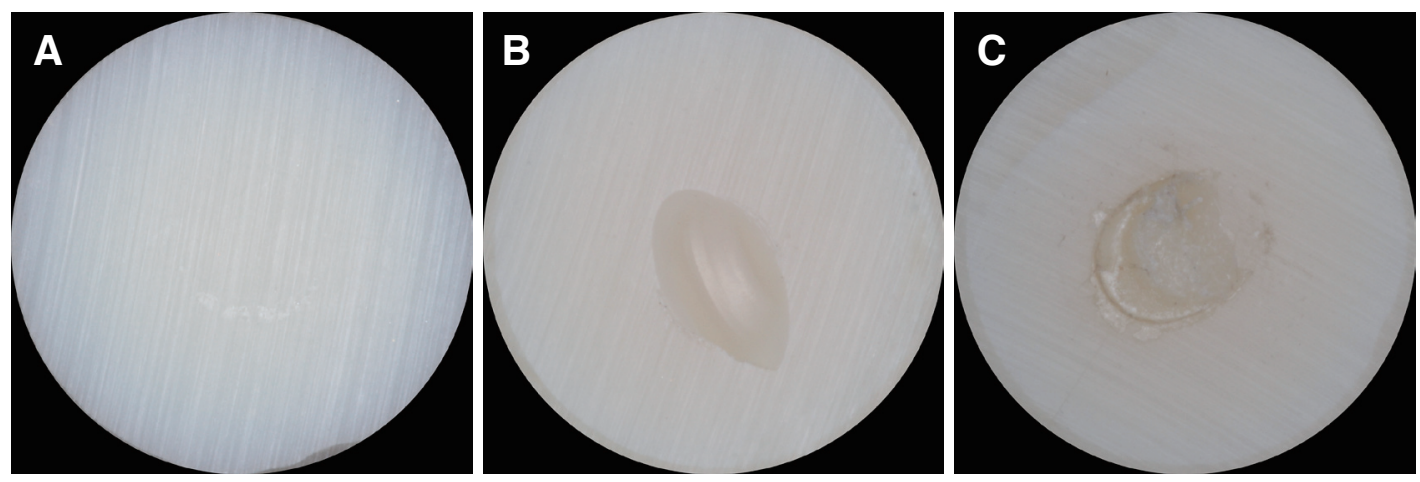

Fig. 3. Failure mode of specimens. (A) Adhesive failure, (B) Cohesive failure, (C) Mixed failure. 
Table 3. Failure mode of all specimens

\begin{tabular}{lcccccccccc}
\hline & A1 & A2 & A3 & B1 & B2 & B3 & C1 & C2 & C3 \\
\hline Adhesive failure & 10 & 2 & 6 & 8 & 5 & 7 & 7 & 3 & 8 \\
Cohesive failure & 0 & 3 & 2 & 0 & 2 & 2 & 1 & 2 & 1 \\
Mixed failure & 0 & 5 & 2 & 2 & 3 & 1 & 2 & 5 & 1 \\
\hline
\end{tabular}

Table 4. Spearman's rank correlation analysis results between shear bond strengths and failure modes

\begin{tabular}{lllll}
\hline & & Ad & Co & Mi \\
\hline \multirow{2}{*}{ Shear bond strengths } & $\sigma$ & -.429 & .413 & .351 \\
& $\mathrm{p}$ & .250 & .269 & .355 \\
\hline
\end{tabular}

๘: Spearman correlation coefficient; p: Significance value; Ad: Adhesive failure; Co: Cohesive failure; Mi: Mixed failure.

\section{고찰}

레진의 중합은 시간이 지날수록 진행되어 폴리머 사슬 이 더욱 견고 해진다. 따라서, 미반응 혹은 활성화된 라디 칼이 남아있지 않게 되어 새롭게 부착된 수리 물질의 결 합력이 떨어지게 된다. 또한, 미세 틈에 스며든 물 분자가 새로운 물질의 부착을 막는다. 본 실험에서 15 일간 $37^{\circ} \mathrm{C}$ 에서 보관한 후 수리 재료 접착을 시행한 경우의 전단 결 합강도 값이 즉시 수리한 경우보다 낮게 나타난 것도 이 러한 이유 때문일 것이라 생각된다. 열 순환처리를 시행 한 후 수리를 시행하여 전단 결합강도를 측정한 다른 실 험에서도 비슷한 결과를 보고 하였다. ${ }^{11}$

임시 수복용 레진의 수리 시 접착 강도를 높이기 위해 표면의 오염물질은 깨끗이 제거되어야 한다. 따라서 수 리하는 단계 이전에 레진의 표면을 삭제하는 것이 중요 하다. 많은 연구들에서 제시된 접착 강도를 높이기 위한 부가적인 단계로는 사면 혹은 둥근 표면의 형성, ${ }^{12}$ 회전 절삭 기구로 표면을 거칠게 만드는 것, ${ }^{13}$ 인접면 박스를 형성하는 것, ${ }^{14}$ 알루미늄 입자를 이용한 공기 분사 방법, 접착 레진을 사용하는 것 ${ }^{15}$ 등 여러 가지가 있다.

본 연구에서는 레진 표면을 \#220 grit 사포를 이용하여 표면의 레진을 삭제한 뒤, 표면처리를 시행하였다. 다른 상업적으로 판매되는 자가부식형 접착제(self-etch adhesives)에 비해 접착 효율이나 내구성 면에서 더 믿을 수 있 는 제품으로 알려진 ${ }^{16}$ Clearfil SE bond (Kuraray dental, Kurashiki, Japan)라는 접착제와 레진의 수리에 효과적 이라고 알려진 ${ }^{17}$ Monobond S (Ivoclar vivadent, Ivoclar vivadent, Schaan, Liechtenstein)라는 실란을 사용하였
다. 접착제와 실란을 적용한 실험군에서 아무것도 적용 하지 않은 실험군 보다 높은 전단 결합강도 값을 얻을 수 있었다. 이는 부가적인 화학적 표면 처리가 접착 강도 증 가에 효과적임을 보여준다. 수리 레진 재료는 높은 점성 으로 인해 표면의 미세구조로 침투하는 것에 한계를 가 진다. 접착제는 재료 표면의 미세구조에 침투하여 미세 기계적 유지력과 함께 화학적 결합을 향상시킨다. ${ }^{18}$

실란은 복합 레진에 있어서 비유기성의 필러 입자와 유 기 레진 중합체를 연결해주는 가교제로 중요한 역할을 담당한다. 실란은 이중반응성(dual reactivity)을 보이는 데, 실란의 유기 기능성 부분은 유기 기질을 중합할 수 있 고, 알콕시 그룹(methoxy, ethoxy)은 무기 물질과 반응할 수 있다. 실란은 이러한 이중반응성을 통해 비슷하지 않 은 무기, 유기기질들 간의 접착을 증진시키는 매개자 역 할을 할 수 있어서 치과계에서 세라믹의 수리, 복합레진 의 필러, 유리섬유나 비귀금속 합금의 표면 처리에 사용 되고 있다. ${ }^{19}$ 본 연구에서도 실란이 레진 수리에 효과적인 것으로 밝혀졌는데, 표면 처리 재료로 실란을 사용한 실 험군 에서 접착제를 사용한 실험군 보다는 낮은 전단 결 합강도 값을 보였으나 유의성 있는 차이를 보이지는 않 았고, 아무것도 처리하지 않은 군보다는 유의성 있게 높 은 전단 결합강도 값을 보였다.

하지만, 실란의 장기적 영향에 대해서는 아직 불명확한 것이 사실이다. 실란의 주요 문제는 장기적으로 가수분 해에 취약하다는 것인데, 레진 표면에 반드시 포함되어 있을 물 분자로 인해 실란과 레진 간의 결합이 약해질 수 있다. ${ }^{20}$ 본 연구의 수리 지연 시간에 따른 비교에서, 즉시 수리한 실험군 들과 15 일 지연 수리한 실험 군들 간의 전 
단 결합강도 값의 유의성 있는 차이는 실란을 사용한 실 험군 에서만 나타났다. 따라서 레진 수리에 있어 실란의 활용은 아직 근거가 부족하며, 이에 대해서는 좀 더 많은 연구가 필요할 것으로 보인다.

비스 아크릴 복합 레진은 비친수성 이며, bis-GMA와 비슷한 물질이다. 비스 아크릴 복합 레진은 다른 복합물 질들과 호환이 가능하나, 수리나 첨가가 어렵다는 단점 이 있다. ${ }^{21}$ Chen 등의 여러 가지 임시 수복용 레진을 이 용한 전단 결합강도 시험에서, 비슷한 화학적 구조를 갖 는 재료 간의 결합 강도가 더 높다는 사실이 밝혀졌다. PMMA 레진은 methacrylate 계열의 재료로 수리했을 때, 비스 아크릴 복합 레진은 복합 레진 계열의 재료로 수 리했을 때 높은 전단 결합강도 값을 보였다. ${ }^{22}$ 본 연구에 서도 비스 아크릴 복합 레진을 PMMA 레진으로 수리했 을 때 보다 광중합형 유동성 복합 레진으로 수리하였을 때 더 높은 전단 결합강도 값을 보였다. 하지만, 아무것 도 처리하지 않고 광중합형 유동성 복합레진으로 수리한 실험군 보다는 표면처리 후 PMMA 레진으로 수리한 군 에서 높은 전단 결합강도를 보였기 때문에, 비스 아크릴 복합 레진과 PMMA 레진 간의 약한 결합 강도를 표면처 리를 통해 개선이 가능할 것으로 생각된다.

본 연구에서는 시편의 파절 양상을 관찰하였고, 두 물 질 간의 결합이 강할수록 혼합 파절이나 응집 파절 양상 이 강할 것으로 예상되었다. 하지만 Spearman의 순위상 관분석에서 전단 결합강도 값과 파절 양상 간에 일정한 상관관계가 나타나지 않았다.

본 연구에서는 비스 아크릴 복합 레진을 PMMA 레진 으로 수리하는 것의 효용성을 알아보고자 지연시간, 표 면처리에 따른 실험군을 설정하였고, 기존에 추천되었던 재료인 광중합형 유동성 복합 레진으로 수리한 실험군을 설정하여 전단 결합강도 값을 비교하고자 하였다. 수리 를 지연시켜 광중합형 유동성 복합 레진으로 수리한 실 험군을 설정하지 않아 수리 지연시간이 수리에 미치는 영 향을 명확히 밝히지 못한 것이 본 연구의 아쉬운 점이다. 또한 다른 아쉬운 점은, 표면 처리에 있어서 실험 조건의 다양성이 부족했다는 점이다. 본 연구에서 수리단계를 간소화하고자 접착제와 실란을 단독으로 적용한 실험군 만 설정하였는데, 실험에서 다루지 않은 다양한 기계적인 표면처리와 더불어 다양한 종류의 접착제, 실란의 조합 을 통한 추가적인 연구를 통해 비스 아크릴 복합 레진을 PMMA 레진으로 수리하기 위한 더 효과적인 방법을 찾 을 수 있을 것이라 판단된다.

\section{결론}

본 연구에서는 임시 수복용 비스 아크릴 복합 레진의 수리 시 지연시간, 표면처리, 수리재료에 따른 전단 결합 강도를 비교하였고, 수리가 지연되지 않았을 때 접착제 를 이용하여 광중합형 유동성 복합 레진으로 수리한 실 험군에서 가장 높은 전단 결합강도 값을 보였다. 따라서 이 제한된 연구결과에 따르면, 임시 레진 수복물의 수리 시 경과시간에 따라 재제작 여부를 고려해야 하며, 효과 적인 수리를 위해 사용부위나 목적에 따라 알맞은 재료 와 표면처리 방법을 고려하는 것이 바람직할 것이다.

\section{Acknowledgements}

This paper was supported by Wonkwang University in 2017 .

\section{ORCID}

Jae-In Lee https://orcid.org/0000-0002-3026-0693

Ji-Su Park https://orcid.org/0000-0001-6480-2588

\section{References}

1. Patras M, Naka O, Doukoudakis S, Pissiotis A. Management of provisional restorations' deficiencies: a literature review. J Esthet Restor Dent 2012; 24:26-38.

2. Michalakis K, Pissiotis A, Hirayama H, Kang K, Kafantaris N. Comparison of temperature increase in the pulp chamber during the polymerization of materials used for the direct fabrication of provisional restorations. J Prosthet Dent 2006;96:418-23.

3. Young HM, Smith CT, Morton D. Comparative in vitro evaluation of two provisional restorative materials. J Prosthet Dent 2001;85:129-32.

4. Schwantz JK, Oliveira-Ogliari A, Meereis CT, Leal FB, Ogliari FA, Moraes RR. Characterization of bis-acryl composite resins for provisional restorations. Braz Dent J 2017;28:354-61.

5. Hammond BD, Cooper JR 3rd, Lazarchik DA. Predictable repair of provisional restorations. J Esthet Restor Dent 2009;21:19-24; discussion 25. 
6. Donovan TE, Hurst RG, Campagni WV. Physical properties of acrylic resin polymerized by four different techniques. J Prosthet Dent 1985;54:522-4.

7. Chee WW, Donovan TE, Daftary F, Siu TM. Effect of chilled monomer on working time and transverse strength of three autopolymerizing acrylic resins. J Prosthet Dent 1988;60:124-6.

8. Eliasson ST, Tibballs J, Dahl JE. Effect of different surface treatments and adhesives on repair bond strength of resin composites after one and 12 months of storage using an improved microtensile test method. Oper Dent 2014;39:206-16.

9. Staxrud F, Dahl JE. Role of bonding agents in the repair of composite resin restorations. Eur J Oral Sci 2011;119:316-22.

10. Shim JS, Lee JY, Choi YJ, Shin SW, Ryu JJ. Effect of light-curing, pressure, oxygen inhibition, and heat on shear bond strength between bis-acryl provisional restoration and bis-acryl repair materials. J Adv Prosthodont 2015;7:47-50.

11. Balkenhol M, Meyer M, Michel K, Ferger P, Wöstmann B. Effect of surface condition and storage time on the repairability of temporary crown and fixed partial denture materials. J Dent 2008;36:86172.

12. Ward JE, Moon PC, Levine RA, Behrendt CL. Effect of repair surface design, repair material, and processing method on the transverse strength of repaired acrylic denture resin. J Prosthet Dent 1992;67:815-20.

13. Cavalcanti AN, De Lima AF, Peris AR, Mitsui FH, Marchi GM. Effect of surface treatments and bonding agents on the bond strength of repaired composites. J Esthet Restor Dent 2007;19:90-8; discussion 99.

14. Appleby DC. Repair of fractured connectors in a provisional fixed partial denture. J Prosthet Dent 2001;86:449-50.

15. Hagge MS, Lindemuth JS, Jones AG. Shear bond strength of bis-acryl composite provisional material repaired with flowable composite. J Esthet Restor Dent 2002;14:47-52.

16. Van Meerbeek B, Yoshihara K, Yoshida Y, Mine A, De Munck J, Van Landuyt KL. State of the art of self-etch adhesives. Dent Mater 2011;27:17-28.

17. Rathke A, Tymina Y, Haller B. Effect of different surface treatments on the composite-composite repair bond strength. Clin Oral Investig 2009;13:31723.

18. Wendler M, Belli R, Panzer R, Skibbe D, Petschelt A, Lohbauer U. Repair Bond Strength of Aged Resin Composite after Different Surface and Bonding Treatments. Materials (Basel) 2016;9:E547.

19. Matinlinna JP, Lassila LV, Ozcan M, Yli-Urpo A, Vallittu PK. An introduction to silanes and their clinical applications in dentistry. Int J Prosthodont 2004;17:155-64.

20. Staxrud F, Dahl JE. Silanising agents promote resin-composite repair. Int Dent J 2015;65:311-5.

21. Burns DR, Beck DA, Nelson SK; Committee on Research in Fixed Prosthodontics of the Academy of Fixed Prosthodontics. A review of selected dental literature on contemporary provisional fixed prosthodontic treatment: report of the Committee on Research in Fixed Prosthodontics of the Academy of Fixed Prosthodontics. J Prosthet Dent 2003;90:474-97.

22. Chen HL, Lai YL, Chou IC, Hu CJ, Lee SY. Shear bond strength of provisional restoration materials repaired with light-cured resins. Oper Dent 2008; 33:508-15. 


\section{수리된 비스 아크릴 복합 레진의 전단결합강도에 대한 지연시간, 표면처리, 수리 재료의 영향}

\section{박지수, 이재인*}

원광대학교 치과대학 치과보철학교실

목적: 본 연구의 목적은 비스 아크릴 복합 레진의 수리 시 지연시간, 표면처리, 수리재료가 미치는 영향을 전단 결합강도 비교를 통해 알아보고, 폴리메틸 메타크릴레이트 레진을 이용한 비스 아크릴 복합 레진 수리의 효용성을 평가하고자 하 는 것이다.

연구 재료 및 방법: 총 90 개의 비스 아크릴 복합 레진 시편을 제작하였고, 지연시간, 표면처리, 수리재료에 따라 10 개씩 9 개의 실험군으로 분류하였다. 각각의 시편들은 제작 직후 만능시험기를 사용하여 전단 결합강도를 측정하였고, 통계분 석 프로그램(IBM SPSS statistics 20)을 이용하여 분석하였다. 전단 결합강도 측정 후 시편의 파절 단면을 관찰하였다.

결과: 시편 제작 직후, 접착제(bonding agent)를 이용하여 광중합형 유동성 복합 레진을 접착한 실험군에서 가장 높은 전 단 결합강도를 보였다(17.54 $\pm 3.14 \mathrm{MPa})$.

결론: 비스 아크릴 복합 레진을 수리할 때 경과시간에 따라 재제작 여부를 고려해야 하며, 효과적인 수리를 위해 사용부 위나 목적에 따라 알맞은 재료와 표면처리 방법을 고려하는 것이 바람직할 것이다.

(구강회복응용과학지 2018;34(2):89-96)

주요어: 비스 아크릴 복합 레진; 폴리메틸 메타크릴레이트 레진; 접착제; 실란; 임시 수복물 수리 